\title{
Visão da equipe multiprofissional do Programa Saúde da Família acerca da integralidade das ações preconizadas pelo Ministério da Saúde
}

Aldaíza Ferreira Antunes Fortes, M.Sc. ${ }^{*}$, Ana Maria Nassar Cintra Soane, M.Sc. ${ }^{* *}$, Adriana Rosa dos Reis***

*Enfermeira, Docente da disciplina Estágio Supervisionado, do Curso de Graduação em Enfermagem, da Escola de Enfermagem Wenceslau Braz (EEWB), Responsável pelo Setor de Pesquisa e Estudos Acadêmicos da EEWB, ${ }^{* *}$ Enfermeira, Coordenadora do Departamento de Ensino e Pesquisa da EEWB, ${ }^{* * *}$ Enfermeira, Especialista em Saúde da Familia, pela EEWB, Enfermeira RT, da Unidade Básica de Saúde Maria Gonçalves Siqueira, São José do Alegre/MG

\section{Resumo}

Trata-se de um estudo qualitativo, exploratório-descritivo, cujo objetivo foi conhecer a visão da equipe multiprofissional do Programa Saúde Família (PSF), do município de São José do Alegre/MG, acerca da integralidade das açóes preconizadas, pelo Ministério da Saúde (MS). Os sujeitos foram nove membros da equipe multiprofissional do PSF em questáo. Os dados foram coletados, em julho de 2008, por meio de um roteiro de entrevista semi-estruturada. Para seis participantes a integralidade das açóes preconizadas pelo MS está sendo aplicada na prática cotidiana da sua equipe de trabalho. Constatou-se que os entrevistados vivenciam momentos de desarticulação de suas açôes e uma desintegração entre eles, ocorrendo a necessidade de integração, trabalho em equipe, preparo adequado dos profissionais que favoreça a credibilidade dos mesmos ao programa e unificação dos três setores da saúde: atenção primária, secundária e terciária.

Palavras-chave: equipe multiprofissional, Programa Saúde da Família, assistência à saúde.

\section{Abstract \\ Vision of multiprofessional team of Family Health Program about comprehensive actions recommended by Ministry of Health}

This qualitative exploratory-descriptive study aims at knowing the vision of the multiprofessional team of Family Health Program (FHP), of São José do Alegre/MG, concerning comprehensive actions recommended by Ministry of Health (MH). Nine subjects composed the multiprofessional team of this FHP. Data were collected on July 2008 using a semi-structured interview guide. For six participants the comprehensive actions recommended by $\mathrm{MH}$ are applied during daily practice of its group work. It was evidenced that the participants experience moments of disconnection of their actions and disintegration among them. Based on this, they see the need for integration; work as a team, adequate professional preparation which should favor the program credibility and unification of the three health care sectors: primary, secondary and tertiary health care.

Key-words: multiprofessional team, Family Health Program, health care. 


\section{Resumen \\ Visión del equipo multiprofesional del Programa de Salud Familiar sobre la integralidad de las medidas preconizadas por el Ministerio de la Salud}

Se trata de estudio cualitativo, exploratorio-descriptivo cuyo objetivo fue conocer la visión del equipo multiprofesional del Programa de Salud Familiar (PSF), de la ciudad Sáo José de Alegre - MG, acerca de la integralidad de las acciones preconizadas por el Ministerio de la Salud (MS). Los sujetos fueron nueve miembros del equipo multiprofesional del PSF en cuestión. Los datos fueron recolectados durante el mes de Julio del 2008, utilizando un guión de entrevista semiestructurada. Para seis participantes la integralidad de las acciones preconizadas por el MS se está aplicando en la práctica diaria de su equipo de trabajo. Se evidenció que los entrevistados experienciaron momentos de desarticulación de sus acciones y una desintegración entre ellos. Por lo tanto, existe la necesidad de integración, trabajo en equipo, preparación adecuada de los profesionales que favorezcan la credibilidad del programa y unificación de los tres niveles de atención en salud: primaria, secundaria y terciaria.

Palabras-clave: equipo multiprofesional, programa de salud familiar, prestación de atención de salud.

\section{Introdução}

O Programa Saúde da Família (PSF) propóe uma nova dinâmica no serviço de saúde, no nível de Atenção Primária. Trata-se de reorganizar a prática assistencial, em novas bases, e substituir o modelo tradicional produtor de procedimentos, pela produção de cuidados, entendido enquanto ações de acolhimento, vínculo, autonomização e resolução [1].

O PSF incorpora e reafirma os princípios do Sistema Único de Saúde (SUS) que está estruturado da seguinte forma: caráter substitutivo das práticas tradicionais, complementariedade e hierarquização, adscrição de população/territorialização, programação e planejamento descentralizados, integralidade da assistência e abordagem multiprofissional. Esta nova proposta de reorganização da Atenção Básica apresenta potencial, para intervir no processo saúdedoença, pois, por meio da equipe multiprofissional é possível estabelecer vínculos, compromissos, novas atitudes, novas possibilidades, satisfação, interação e resultados.

A equipe multiprofissional do PSF apresenta uma composição mínima, constando de um médico, um enfermeiro, um auxiliar de enfermagem e quatro a seis agentes comunitários de saúde. Deve atender uma clientela de no máximo 4.500 pessoas. Representa o elo entre a família e o serviço de saúde. É considerada a parte dinâmica do programa, e depende de vários fatores para se manter, como, por exemplo, o apoio dos gestores. Se isso não ocorrer, o PSF poderá se atomizar, em milhares de modelos de atenção à saúde, reproduzindo os velhos males do sistema, como iniquidade, pouca resolutividade, insatisfação profissional e das famílias/comunidade [2].
Embora o Ministério da Saúde (MS) tenha elaborado a organização e a forma de trabalho, enfocando a equipe multiprofissional, nada garante que haverá ruptura com a dinâmica médico-centrada do modelo hegemônico atual. $\mathrm{O}$ programa não opera de modo amplo, nos micro processos do trabalho em saúde, nos fazeres do cotidiano de cada profissional, que define o perfil da assistência [1].

É importante que a atenção às famílias esteja pautada, em uma equipe multiprofissional e com prática interdisciplinar. A interdisciplinaridade pressupóe, além das interfaces disciplinares tradicionais, a possibilidade da prática de um profissional se reconstruir na prática do outro. Valorizar os diversos saberes e práticas, na perspectiva de uma abordagem integral e resolutiva, possibilitando a criaçáo de vínculos com ética, compromisso e respeito [3].

Se ocorrer uma fragmentação de saberes, em que cada profissional traça seu objetivo isoladamente, corre-se o risco de repetir o modelo de atenção desumanizada, fragmentada, centrada na recuperação biológica individual, com rígida divisão do trabalho e desigual valoração social dos diversos trabalhos.

Uma das autoras deste estudo, desde seu tempo de acadêmica de enfermagem, estagiando em um PSF e, hoje, como profissional, atuando na rede de Atenção Básica, observa que o quadro é esse: uma equipe, muitas vezes, fragmentada; poucos créditos por parte de alguns profissionais, levando à rotatividade dos mesmos; e uma desarticulaçáo do sistema de saúde.

Frente a essas colocações, surgem as indagações: 1. Esses fatores podem interferir, na visão da equipe multiprofissional, acerca da integralidade das açóes preconizadas pelo MS? 
2. Caso interfiram, essa interferência pode fazer com que estes profissionais adotem uma atitude contraditória ao que é preconizado pelo MS?

O trabalho em equipe é fundamental para se obter bons resultados e, a credibilidade ao programa precisa partir da própria equipe multiprofissional, acrescida da articulação do sistema de saúde.

$\mathrm{O}$ atendimento integral garantido pelo princípio do SUS e expresso em atividades preventivas, sem prejuízo dos serviços assistenciais, foi uma proposta desde o início do PSF. Tem uma dupla dimensão, ou seja, uma com o sentido de articular as açóes de promoção da saúde, de prevençáo de riscos e agravos assistenciais, em todos os níveis organizacionais, do sistema de serviços de saúde; e outra relativa à integralidade do sistema de serviços e a construção dos chamados sistemas integrados [2].

Existe uma crítica acerca da integralidade, no contexto da construçáo do SUS, a qual sugere organizar o princípio da integralidade, em três grandes conjuntos de sentidos, considerando que este termo afirma uma recusa ao reducionismo, à objetivação dos sujeitos e uma possível abertura ao dialogo intersubjetivo, como forma de apreensáo ampliada, das necessidades de açóes e serviços sintonizados com a contextura de cada encontro [2].

Diante do exposto, este estudo tem como objetivo conhecer a visão da equipe multiprofissional do PSF, do município de São José do Alegre/MG, acerca da integralidade das açóes preconizadas pelo MS.

\section{Material e métodos}

Trata-se de uma pesquisa exploratória-descritiva, de abordagem qualitativa, realizada com nove membros da equipe multiprofissional do PSF, do município de São José do Alegre, estado de Minas Gerais, ou seja, um médico, um enfermeiro, dois auxiliares de enfermagem e cinco agentes comunitários de saúde.

O tipo de amostragem foi intencional.

A coleta de dados se deu por meio de um roteiro de entrevista semi-estruturada constituído por duas partes, sendo a primeira referente às características pessoais e profissionais dos entrevistados e a segunda abordou três questôes abertas relacionadas com o objetivo do estudo.

Antes da utilização definitiva, deste roteiro, foi realizado um pré-teste, com cinco membros da Unidade Saúde da Família do Município de Pedralva/MG, sendo que eles náo fizeram parte da amostra deste estudo.

O pré-teste serviu para identificar três importantes elementos: fidedignidade, validade e operatividade [4]. Após sua realização, averiguou-se que não era necessário alterar o roteiro de entrevista semi-estruturada elaborado.

As entrevistas ocorreram no mês de julho de 2008 e foram gravadas em fitas cassetes, as quais, após a transcrição dos dados, foram incineradas.

Os dados coletados foram transcritos, permitindo a fidedignidade das informaçóes colhidas. Em seguida, foram analisados e interpretados por meio da análise do conteúdo [5].

A análise de conteúdo é a técnica mais difundida para investigar o conteúdo das comunicações, mediante a classificaçáo, em categorias, dos elementos da comunicação. Consiste na descoberta dos núcleos de sentido que compóem uma comunicação, de forma que a presença ou frequência seja significativa para o objetivo analítico visado [6]. Preservou-se a confidencialidade e o anonimato de todos os participantes da pesquisa, utilizando as seguintes denominaçóes que fazem parte do cotidiano da equipe: saúde, qualidade, assistência, acolhimento, vida, vínculo, responsabilidade, atuação e trabalho.

Para este estudo, foram atendidas, criteriosamente, as recomendaçóes expressas na Resolução n ${ }^{\circ}$. 196/96, do Conselho Nacional de Saúde, concernentes à realizaçáo de pesquisas com seres humanos [7]. Portanto, iniciou-se a coleta de dados somente após a aprovação, do Comitê de Ética em Pesquisa, da Escola de Enfermagem Wenceslau Braz.

\section{Resultados e discussão}

Em relação aos dados característicos dos sujeitos da pesquisa, dois sáo do sexo masculino e sete do sexo feminino; a idade média dos entrevistados situa-se na faixa etária de 24 a 39 anos e o tempo de trabalho, na equipe multiprofissional, varia de um a três anos.

Observou-se que a equipe multiprofissional do PSF envolvida no estudo é composta por indivíduos adolescentes e adultos jovens, há uma predominância do gênero feminino (78\%) e possui um tempo de convivência de, no máximo, três anos.

Ao analisar os dados da primeira questáo "O que você sabe sobre a integralidade das açóes 
preconizadas pelo MS, para a atuação da equipe multiprofissional do PSF?", evidenciaram-se cinco categorias: integração e trabalho em equipe; resolutividade; criação de vinculos; atendimento por inteiro; divisão de tarefas.

$\mathrm{Na}$ categoria integração e trabalho em equipe pode-se perceber que, para esses profissionais, a integralidade das açóes está relacionada com o processo de trabalho desenvolvido diariamente na equipe. Cada trabalhador de saúde é um elemento indispensável e que, a partir de um trabalho em equipe, forma-se um produto final, para suprir as necessidades do usuário, ou seja, prestar uma assistencial integral.

Isso é sinalizado nos seguintes depoimentos:

"Integralidade é a integração da equipe, sempre um disposto a ajudar o outro (...)" (Vinculo).

“(...) e a equipe de saúde deve trabalhar sempre em equipe, para dar continuidade ao serviço prestado à população.” (Responsabilidade).

O trabalho em equipe representa um dos pilares de sustentação do PSF, pois quando efetivo leva à construção do projeto de saúde da família, o qual deve ser norteado por uma proposta assistencial comum em que os agentes desenvolvam uma ação de interação entre si e a comunidade.

Observou-se na categoria resolutividade que a integralidade das açóes está diretamente relacionada com a continuidade à assistência e à solução dos problemas encontrados, como demonstram os relatos:

“(...) Ter sempre uma resposta ou solução para dar ao paciente.” (Vínculo).

“(...) procuramos trabalhar sempre unidas, tentando da melhor maneira resolver os problemas do município." (Atuação).

O PSF constitui-se de equipes multiprofissionais, que devem atuar em uma perspectiva interdisciplinar. Os membros da equipe articulam suas práticas e saberes no enfrentamento de cada situação identificada, para propor soluçôes conjuntamente e intervir de maneira adequada e resolutiva.

Um dos maiores desafios do SUS vem sendo melhorar a Atenção Primária, pois é nesse nível que se resolve $90 \%$ dos problemas mais comuns. A resolutividade acontece a custos mais baixos e com maior impacto, sobre os níveis de saúde e sobre a qualidade de vida da população [8].

"O PSF pode ser definido como um modelo de atenção, que pressupóe o reconhecimento de saúde, com um direito de cidadania expresso, na melhoria das condiçóes de vida, no que toca à área da saúde essa melhoria deve ser traduzida em serviços mais resolutivos (...)" [9].

Examinando a categoria, criação de vínculos, notou-se que a postura acolhedora do profissional da saúde, ao buscar alternativas, para dar continuidade à assistência e solucionar os problemas da comunidade, possibilita o estabelecimento de vínculos com o usuário, e estabelece relaçôes tão próximas e claras, que favorecem ao cuidado integral. $\mathrm{O}$ trabalhador da saúde inserido, neste contexto, sensibiliza-se e foge aos padróes de intervençôes burocráticas e impessoais. Isso é expresso na fala a seguir:

“(...) Entende-se como integralidade um grupo de pessoas tendo interesses comuns e um relacionamento considerado harmonioso. Neste caso entre a equipe e as pessoas que assistimos." (Acolhimento).

A vinculação dos profissionais e serviços com a comunidade constitui um dos objetivos do PSF [10].

A recuperação da prática clínica, assentada no vínculo, é a maneira prática de se combinar autonomia e responsabilidade profissional. A assistência baseada no vínculo permite que o serviço de saúde acompanhe e identifique os resultados dos trabalhos de cada profissional, oferecendo, na prática, a cidadania pelo paciente e pela família [11].

Interpretando a categoria atendimento por inteiro reconheceu-se que a integralidade das açóes pode ser entendida como uma assistência que visa o todo, integral, inteiro, ou seja, não se pode reduzir o usuário em partes, como é registrado nos enunciados:

"É um atendimento por um todo e não por partes" (Assistência).

"A integralidade das açốes é muito importante, pois favorece uma visão panorâmica do paciente" (Qualidade). 
"Integral deve ser tudo. Bom, abrange tudo. Dar aquele atendimento que o paciente precisa atendimento por inteiro" (Atuação).

Dentre as finalidades do PSF estão: a reorganização do modelo assistencial, com o fortalecimento da atenção à saúde; a ênfase na integralidade da assistência; o tratamento ao indivíduo como ser integral, ligado à família, ao domicílio e à comunidade [10].

"A equipe de saúde do PSF tem o compromisso de promover a saúde e elevar a qualidade de vida da população, não só com intervençóes epidemiológicas e sanitárias, mas considerando o contexto biopsicossocial do ser humano" [11].

$\mathrm{Na}$ categoria, divisão de tarefas, evidenciou-se que o trabalho em saúde, assim como no PSF, acontece quando nós nos relacionamos. Para desenvolver uma tarefa, temos um fazer conjunto, que precisa ser maior do que a soma das parcelas do trabalho de cada um dessa equipe. Isso é ilustrado no seguinte depoimento:

“O Ministério da Saúde já percebeu que onde tem equipe multiprofissional o rendimento será sempre melhor, pois a divisão de tarefas vai sempre favorecer o bom rendimento da equipe." (Saúde).

É preciso ter alguém para fazer as visitas domiciliares, que medique, prescreva, aplique, ensine e oriente. Cada integrante da equipe possui um saber, uma história de vida, uma formação específica e, com isso, a tendência é a de náo considerarmos tais diferenças e trabalharmos, como numa fábrica, onde cada um faz um pedaço: um aperta o parafuso, outro pinta, e outro embala. O produto final é mérito de toda a equipe [12].

Ao analisar as respostas dos entrevistados à segunda questão: "Você acha que a integralidade das açóes preconizadas, pelo MS, está sendo aplicada na prática cotidiana da sua equipe multiprofissional?", verificou-se que, dos nove participantes $66,67 \%$ (seis) responderam SIM e 33,33\% (três) responderam NÃO.

As justificativas dos sujeitos da pesquisa, que optaram pela alternativa SIM, revelaram três categorias: integração e trabalho em equipe; profissionalismo e; discussáo dos deveres, objetivos e soluçóes das açóes em benefício do paciente. Para estes indivíduos a integralidade das açóes, preconizadas pelo MS está sendo aplicada na prática cotidiana da sua equipe de trabalho, porque eles vivenciam estas categorias.

$\mathrm{Na}$ categoria integração e trabalho em equipe identificou-se que as práticas cotidianas da equipe se responsabilizam pela integralidade das açóes, ou seja, é no dia a dia da equipe que se identifica a integralidade das açóes, presente no trabalho coletivo. $\mathrm{O}$ trabalho, em equipe, favorece a continuidade do acompanhamento e o maior envolvimento com as famílias, por meio da abordagem de toda a equipe multiprofissional. Isso é descrito nas seguintes falas:

"Porque trabalhamos em equipe, um ajudando o outro." (Vínculo).

"Em nossa equipe acontece a integralidade das ações, pois trabalhamos em equipe, profissionais junto com pacientes, dando continuidade ao serviço para com a saúde do paciente, em todos os momentos." (Responsabilidade).

"Apesar dos conflitos, trabalhamos em equipe e de forma integrada, procurando muitas vezes passar o problema do paciente para o médico e para enfermeira; até mesmo quando náo conseguimos resolver passamos para UBS.” (Atuação)

"Porque trabalhamos em equipe." (Qualidade).

O trabalho em equipe é um dos fatores que garante o funcionamento do PSF e se isso não ocorrer, esta estratégia poderá se atomizar em milhares de modelos de atenção à saúde, reproduzindo os velhos males do sistema: ineficiência, iniquidade, pouca resolutividade, insatisfação profissional e das famílias [2,13].

O principio da integralidade dá a garantia de integraçáo da equipe de saúde no atendimento ao usuário [14]. Compreendendo a categoria Profissionalismo percebeu-se que, para esse novo chamado, que é o PSF, precisa-se de profissionais com uma visão diferente. Profissionais que adotem posturas profissionais, que saibam quais são suas competências, responsabilidades e atribuições. Os seguintes depoimentos sinalizam a categoria acima: 
"Porque trabalhamos com profissionalismo." (Vínculo).

"No local onde trabalho. A equipe é bem estruturada, discutimos todas as tarefas, sempre com respeito às funçóes de cada um." (Saúde).

Acrescenta-se ao princípio da integralidade a garantia também da definição de competências e responsabilidades, dos membros da equipe, bem como as atribuiçóes de cada profissional responsável pelo cuidado [14].

Analisando a categoria discussão dos deveres, objetivos e soluçóes das açóes em benefício do paciente averiguou-se que a mesma é desenvolvida e aplicada no trabalho coletivo da equipe saúde da família. $\mathrm{O}$ MS preconizou, como um dos elementos centrais, do PSF, o trabalho conjunto da equipe multiprofissional e, com isso, acredita que é possível elaborar e executar açóes, que visem à integralidade das práticas, em favor da qualidade da assistência prestada ao paciente. Isso é evidenciado nas falas:

"São debatidos os deveres, objetivos, soluções e os pacientes recebem ajuda integral. Ocorre a prevenção, promoção, proteção à saúde." (Trabalho).

\footnotetext{
"Na equipe tem integraçáo, pois os agentes comunitários vão até as famílias, descobrem os problemas, passam para a enfermeira, que chega até o médico. Assim tem continuidade e solução para os problemas encontrados." (Vínculo).
}

Da análise das justificativas dos entrevistados, que responderam NÃO à segunda questão, emergiram, também, três categorias: falta de integração e trabalho em equipe; descontinuidade nas açôes de saúde, para concluir o tratamento e, preparo inadequado da equipe. Para estes indivíduos a integralidade das açóes preconizadas, pelo MS, não está sendo aplicada na prática cotidiana da sua equipe de trabalho, porque eles vivenciam estas categorias.

$\mathrm{Na}$ categoria falta de integração e trabalho, em equipe, constatou-se que pode ser um comportamento natural às mudanças, ou seja, é natural que se tenha resistência por partes de alguns integrantes, visto que o PSF é uma proposta nova que veio para modificar o processo de trabalho e redefinir posiçóes referentes aos avanços alcançados com a promoção e vigilância à saúde. Ilustrando esta categoria temse o relato:
"Porque integralidade entra um conjunto de açôes, atitudes, e nem sempre se consegue trabalhar em equipe, pois há um bloqueio, ou seja, entre algumas partes que acabam ocultando fatos e não interagindo com a equipe toda." (Vinculo).

O PSF estabelece uma nova filosofia de trabalho. Isso implica certamente em alguma resistência por parte dos participantes do processo de mudança. Portanto não se pode esperar que a assimilação dessa nova estratégia apresente resultados imediatos. É necessário tempo, para que as boas práticas sejam reconhecidas e disseminadas [15].

$\mathrm{Na}$ categoria, descontinuidade nas açóes de saúde para concluir o tratamento, identificou-se que o profissional da saúde da família está buscando a integralidade das ações, mas não consegue concluir a sua assistência, pois se depara com uma desarticulaçáo do sistema de saúde, no que se refere ao apoio diagnóstico. Através do seguinte depoimento obteve-se essa identificação:

"Às vezes o trabalho do PSF que tem que ser bem feito, elaborado, para ter continuidade, não tem condiçốes financeiras ou é barrado na parte de exames expedidos pelo médico. Entâo esta integralidade, continuidade são podadas ao meio. $\mathrm{O}$ tratamento não é concluído." (Assistência).

O princípio da integralidade dá a garantia da organização dos serviços, que visa o atendimento do usuário, em todos os pontos de atenção, sendo necessária uma rede integrada de serviços de saúde [14]. Em um estudo realizado em 2001/2002, pelo MS, para Avaliação Normativa do PSF, os resultados demonstraram que o apoio diagnóstico e a referência, para atenção especializada, ainda foram insuficientes para garantir a resolutividade $e$ a continuidade da atenção às populaçóes assistidas pelo PSF [16].

Ao analisar a categoria, preparo inadequado da equipe, constatou-se que não basta expor o profissional da saúde a novos cenários de atuação, acreditando que a mudança por si só acontecerá, é preciso preparálo e capacitá-lo, como expresso a seguir: 


\begin{abstract}
"Alguns membros da equipe náo estáo preparados para a execução do trabalho comunitário, sendo assim, o profissional não terá um bom desempenho, para tais funçôes que exerce, deixando passar despercebidas as prioridades." (Acolhimento).
\end{abstract}

Um dos entraves significativos a ser enfrentado, neste processo de expansão do PSF e seu impacto sobre a organização e resolutividade do sistema de saúde é o que se refere à questão dos recursos humanos, merecendo destaque aos aspectos relacionados à formação dos profissionais, despreparo e precária qualificaçáo dos mesmos [2].

A grande maioria das instituiçóes formadoras fragmenta o objeto e o reduz aos limites dos próprios cursos, oferecendo um aprendizado, que continua embasado em guetos, nos quais persiste o conhecimento de cada área, que se limita a atos fragmentados, levando a não produção de profissionais adequados às perspectivas da atenção integral [16].

Os sujeitos da pesquisa, que optaram pela alternativa $\mathrm{NÂO}$, na segunda questão, ao responderem à terceira questáo: "O que você sugere para que a integralidade das açóes preconizadas, pelo MS, seja aplicada na prática cotidiana dos profissionais, atuantes da sua equipe de saúde?" elencaram sugestóes que podem ser ilustradas nas seguintes falas:

"Que haja mais entrosamento da equipe, para que possam repassar problemas, dificuldades para toda a equipe. Assim todos ficarão sabendo de tudo." (Atuação).

"Que tenha mais cumplicidade entre a equipe, para podermos fazer um grande trabalho em equipe." (Atuação).

"O que o profissional de saúde precisa é compreender profundamente os pontos fortes e os pontos fracos da comunidade e suas características especificas, ou seja, dando prioridade, para aqueles que realmente precisam dos serviços comunitários, desenvolvendo a promoção da saúde." (Acolhimento).

"Que todos trabalhem com um só objetivo: o paciente num todo e não por partes." (Assistência).
"As pessoas que competem uma continuidade das açôes, tenham condiçôes para realizálas." (Assistência).

"Que a saúde seja uma só. E não haja separação de UBS com PSF.” (Assistência).

"As pessoas que trabalham devem ser mais preparadas." (Assistência).

Ao analisar estas sugestóes, percebeu-se que, na visão destes profissionais, a integralidade das açóes pode ser alcançada, quando se tem um trabalho em equipe, no qual os integrantes não devem ser um agrupamento de açóes e de agentes e sim uma equipe de integração [12].

O trabalho em equipe está associado à realização de um trabalho compartilhado entre vários indivíduos, que tem objetivo comum a alcançar. $\mathrm{O}$ sucesso é o trabalho coletivo [2].

A integralidade das açóes relacionada com a integração e trabalho em equipe, preparo e capacitação dos profissionais, pode ser denominada de integralidade focalizada, porém, numa visão mais abrangente, podemos denominá-la de integralidade ampliada, onde analisamos as açóes intersetoriais, organização e articulação do sistema de saúde [2].

É importante ressaltar que a integralidade das açóes não se dá por imposiçóes de gestores, em relação à atuação da equipe multiprofissional e sim, a partir do desejo de aderir ao projeto e da discussão conjunta entre gestores, trabalhadores da saúde e usuários/ famílias.

\section{Conclusão}

Ao finalizar este estudo, no qual se buscou conhecer a visão da equipe multiprofissional, acerca da integralidade das açóes preconizadas, pelo MS, percebeu-se que seu desenvolvimento serviu para uma reflexáo sobre a prática da equipe multiprofissional envolvida na pesquisa.

Iniciou-se este estudo, haja vista que se acreditava em um hiato existente sobre o que é preconizado pelo MS, para a atuação da equipe multiprofissional e a prática cotidiana da mesma. Foi escolhido o termo integralidade das açóes, pois, por meio da literatura, pode-se observar que ele engloba todo o processo de trabalho da equipe e acrescenta ainda as limitaçóes do sistema da saúde. 
Dos nove profissionais entrevistados três responderam que a integralidade das ações NÃO está sendo aplicada na prática diária da sua equipe e seis profissionais responderam SIM, ou seja, que a integralidade das açóes está sendo aplicada na prática diária da sua equipe. Para os primeiros, está ocorrendo um hiato que inquieta e que foi a célula propulsora para realização deste trabalho. Estes participantes mencionaram que falta articulação do serviço de apoio diagnóstico, que há despreparo e desqualificaçáo de alguns profissionais e, a falta de integração e trabalho em equipe impossibilitam as práticas que visam à integralidade das açôes.

Constatou-se que os sujeitos do estudo vivenciam momentos de desarticulação de suas açóes, ocorrendo à necessidade de integração, trabalho em equipe, preparo adequado dos profissionais que favoreçam a credibilidade dos mesmos ao programa e unificação dos três setores da saúde: Atenção Primária, Secundária e Terciária.

Averiguou-se, por meio da análise das respostas dos entrevistados, que a integralidade das açóes está diretamente relacionada aos conceitos que os sujeitos atribuem ao trabalho diário da sua equipe multiprofissional.

Evidenciou-se, também, que a integralidade se constrói a partir de açôes objetivas e subjetivas, que são produtos resultantes de relaçôes entre fatores sociais, em suas práticas, no cotidiano dos serviços de saúde.

Nos dias atuais a proposta de trabalhar em equipe não é novidade e na área da saúde é imprescindível, para que o trabalho se concretize. Sabendo que a integralidade das açóes é de suma importância, para a efetividade e resolutividade do PSF, torna-se necessário oferecer uma atenção especial aos participantes deste estudo, procurando solucionar as deficiências detectadas, que estáo impedindo a aplicabilidade da integralidade das açóes preconizadas, pelo MS, na prática cotidiana deles.

Espera-se que este estudo possa favorecer as discussóes sobre a amplitude do tema integralidade das açóes, subsidiando a prática, a formação e a capacitação dos profissionais do PSF, e, também, preencher as lacunas referentes à existência de uma desarticulaçáo do sistema de saúde.

\section{Referências}

1. Franco T, Merhy F. PSF: Contradiçóes e novos desafios. [citado 2007 Jun 10]. Disponível em URL: http://www. datasus.gov.br/cns/temas/tribuna.htm

2. Silva TCS. A construção das práticas de integralidade no cotidiano de uma equipe de Saúde da Família [dissertação]. Belo Horizonte:Universidade Federal de Minas Gerais; 2006.

3. Bertussi DC. Desenvolvimento gerencial em saúde: Limites e possibilidades [dissertação]. Londrina: Universidade Estadual de Londrina; 2002.

4. Marconi MA, Lakatos EM. Técnicas de pesquisa. 5a ed. São Paulo: Atlas; 2002.

5. Marconi MA, Lakatos EM.. Fundamentos de metodologia cientifica. $3^{a}$ ed. São Paulo: Atlas; 1995.

6. Minayo MCS. O desafio do conhecimento: Pesquisa qualitativa em saúde. São Paulo: Hucitec; 1998.

7. Brasil. Resolução 196. Diretrizes e normas regulamentadoras de pesquisas envolvendo seres humanos. Brasília: Diário Oficial da República Federativa do Brasil; 1996.

8. Sousa MN, Braga TW. Princípios da atenção primária à saúde. Oficina de trabalho/saúde em casa e o Programa Saúde da Família. Belo Horizonte: Secretaria de Estado de Saúde de Minas Gerais; 2005. p.31.

9. Rosa GAW, Labate CR. A construção de um novo modelo de assistência. Rev Latinoam Enfermagem 2005;13(6):1-10.

10. Brasil. Ministério da Saúde. Saúde da Família. [citado 2005 maio 15]. Disponível em: URL:http//www. saude.gov.br

11. Oliveira ME, Spiri CW. Programa Saúde da Família: A experiência da equipe multiprofissional. Rev Saúde Pública 2006;40(4):727-733.

12. Fortuna MC, Mishima MS, Matumot S, Pereira BJM. O Trabalho de equipe no Programa Saúde da Família: Reflexóes a partir de conceitos do processo grupal e de grupos operativos. Rev Latinoam Enfermagem 2005;13(2):262-8.

13. Frazili RTV. O enfermeiro e as famílias-necessidades de aperfeiçoamento do enfermeiro na prática com as famílias no Programa Saúde da Família [dissertação]. São Paulo: Universidade Federal de Sáo Paulo; 2006.

14. Avaliação de Programas de Governo/Relatório, Voto e decisão no 649/2002 TCU. Plenário. [citado 2007 Set 10]. Disponível em URL: http://www.tcu.gov.br

15. Brasil. Ministério da Saúde. Secretaria de Atenção à Saúde. Departamento de Atenção Básica. Avaliação Normativa do Programa Saúde da Família no Brasil: monitoramento da implantaçáo e funcionamento das equipes de saúde da família: 2001/2002. Brasília: Ministério da Saúde; 2004.

16. Gontijo DE, Marcolino C, Silva ICM. Interdisciplinaridade na promoção de saúde: relato de experiência em seis cursos de graduação da UFMG. Rev Med Minas Gerais 2007:16(4):129-33. 